\title{
Mixed methods research: expanding the evidence base
}

\section{Allison Shorten, ${ }^{1}$ Joanna Smith ${ }^{2}$}

$10.1136 /$ eb-2017-102699

${ }^{1}$ School of Nursing, University of Alabama at Birmingham, USA ${ }^{2}$ Children's Nursing, School of Healthcare, University of Leeds, UK

\section{Correspondence to:}

Dr Allison Shorten,

School of Nursing, University of

Alabama at Birmingham, 1720

2nd Ave South, Birmingham, AL, 35294, USA; ashorten@uab.edu; ashorten@uab.edu

\section{Introduction}

'Mixed methods' is a research approach whereby researchers collect and analyse both quantitative and qualitative data within the same study. ${ }^{12}$ Growth of mixed methods research in nursing and healthcare has occurred at a time of internationally increasing complexity in healthcare delivery. Mixed methods research draws on potential strengths of both qualitative and quantitative methods, ${ }^{3}$ allowing researchers to explore diverse perspectives and uncover relationships that exist between the intricate layers of our multifaceted research questions. As providers and policy makers strive to ensure quality and safety for patients and families, researchers can use mixed methods to explore contemporary healthcare trends and practices across increasingly diverse practice settings.

This article will outline common types of mixed methods designs and provide examples of how nursing researchers can apply different mixed methods designs in order to answer important nursing practice questions.

\section{What is mixed methods research?}

Mixed methods research requires a purposeful mixing of methods in data collection, data analysis and interpretation of the evidence. The key word is 'mixed', as an essential step in the mixed methods approach is data linkage, or integration at an appropriate stage in the research process. ${ }^{4}$ Purposeful data integration enables researchers to seek a more panoramic view of their research landscape, viewing phenomena from different viewpoints and through diverse research lenses. For example, in a randomised controlled trial (RCT) evaluating a decision aid for women making choices about birth after caesarean, quantitative data were collected to assess knowledge change, levels of decisional conflict,

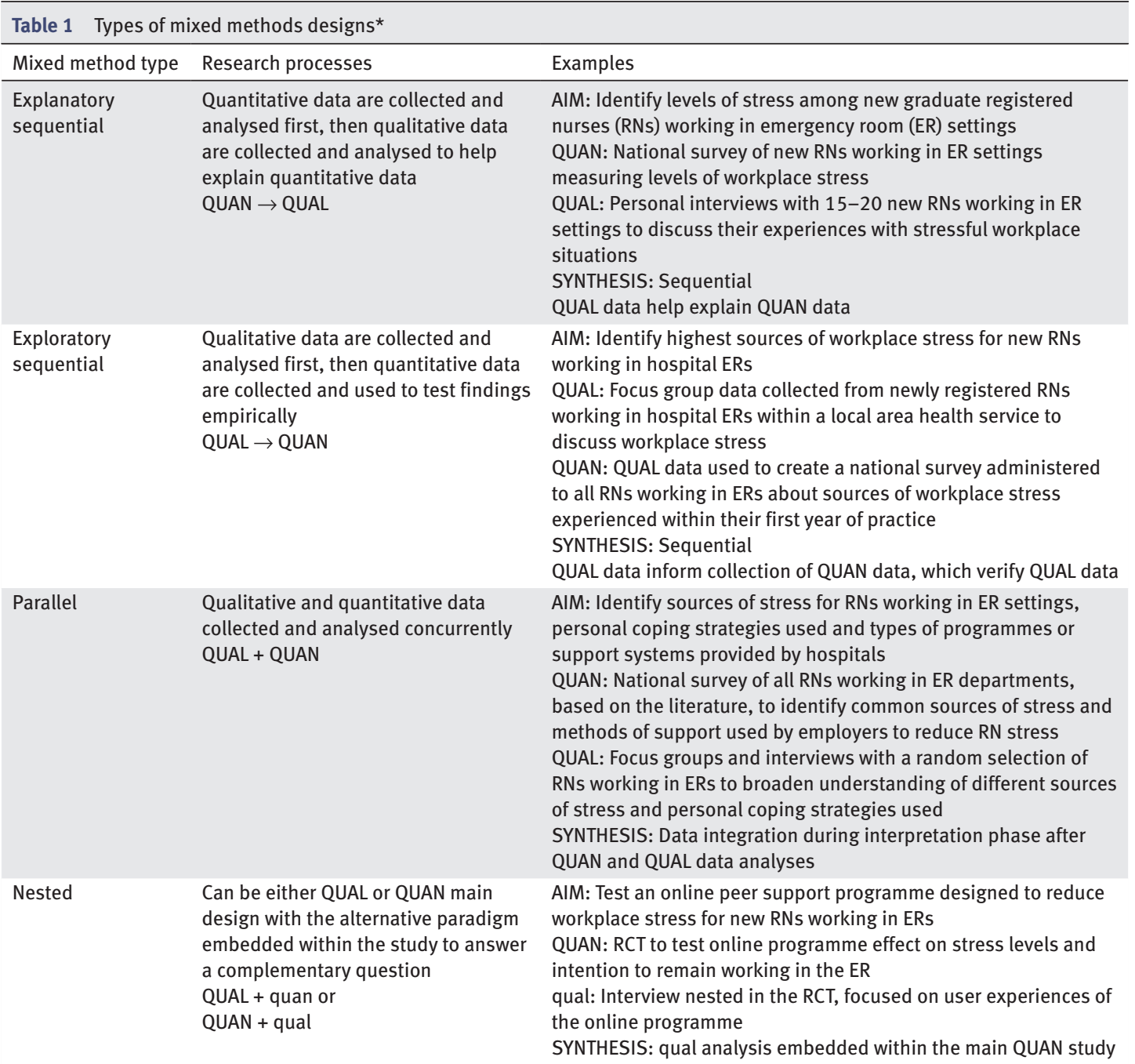

*Table adapted from Halcomb and Hickman. ${ }^{7}$

QUAN, quantitative; QUAL, qualitative. 
birth choices and outcomes. ${ }^{5}$ Qualitative narrative data were collected to gain insight into women's decision-making experiences and factors that influenced their choices for mode of birth. ${ }^{5}$

In contrast, multimethod research uses a single research paradigm, either quantitative or qualitative. Data are collected and analysed using different methods within the same paradigm. ${ }^{67}$ For example, in a multimethods qualitative study investigating parent-professional shared decision-making regarding diagnosis of suspected shunt malfunction in children, data collection included audio recordings of admission consultations and interviews 1 week post consultation, with interactions analysed using conversational analysis and the framework approach for the interview data. ${ }^{8}$

\section{What are the strengths and challenges in using mixed methods?}

Selecting the right research method starts with identifying the research question and study aims. A mixed methods design is appropriate for answering research questions that neither quantitative nor qualitative methods could answer alone. ${ }^{4-11}$ Mixed methods can be used to gain a better understanding of connections or contradictions between qualitative and quantitative data; they can provide opportunities for participants to have a strong voice and share their experiences across the research process, and they can facilitate different avenues of exploration that enrich the evidence and enable questions to be answered more deeply. ${ }^{11}$ Mixed methods can facilitate greater scholarly interaction and enrich the experiences of researchers as different perspectives illuminate the issues being studied. ${ }^{11}$

The process of mixing methods within one study, however, can add to the complexity of conducting research. It often requires more resources (time and personnel) and additional research training, as multidisciplinary research teams need to become conversant with alternative research paradigms and different approaches to sample selection, data collection, data analysis and data synthesis or integration. ${ }^{11}$

\section{What are the different types of mixed methods designs?}

Mixed methods research comprises different types of design categories, including explanatory, exploratory, parallel and nested (embedded) designs. ${ }^{2}$ Table 1 summarises the characteristics of each design, the process used and models of connecting or integrating data. For each type of research, an example was created to illustrate how each study design might be applied to address similar but different nursing research aims within the same general nursing research area.

\section{What should be considered when evaluating mixed methods research?}

When reading mixed methods research or writing a proposal using mixed methods to answer a research question, the six questions below are a useful guide ${ }^{12}$ :

1. Does the research question justify the use of mixed methods?

2. Is the method sequence clearly described, logical in flow and well aligned with study aims?
3. Is data collection and analysis clearly described and well aligned with study aims?

4. Does one method dominate the other or are they equally important?

5. Did the use of one method limit or confound the other method?

6. When, how and by whom is data integration (mixing) achieved?

For more detail of the evaluation guide, refer to the McMaster University Mixed Methods Appraisal Tool. ${ }^{12}$ The quality checklist for appraising published mixed methods research could also be used as a design checklist when planning mixed methods studies.

\section{Competing interests None declared.}

Provenance and peer review Commissioned; internally peer reviewed.

(C) Article author(s) (or their employer(s) unless otherwise stated in the text of the article) 2017. All rights reserved. No commercial use is permitted unless otherwise expressly granted.

\section{References}

1. Bowers B, Cohen LW, Elliot AE, et al. Creating and supporting a mixed methods health services research team. Health Serv Res 2013;48:2157-80.

2. Creswell JW, Plano Clark VL. Designing and conducting mixed methods research. Thousand Oaks, California: Sage Publications, 2011.

3. Greene JC, Caracelli VJ, Graham WF. Toward a conceptual framework for mixed-method evaluation designs. Educ Eval Policy Anal 1989;11:255-74.

4. Ivankova NV. Using mixed methods sequential explanatory design: from theory to practice. Field methods 2006;18:3-20.

5. Shorten A, Shorten B, Kennedy HP. Complexities of choice after prior cesarean: a narrative analysis. Birth 2014;41:178-84.

6. Andrew S, Halcomb EJ. Mixed Method Research. In: Borbasi S, Jackson D, eds. Navigating the maze of research: enhancing nursing \& midwifery practice. 3rd ed. Marrickville, New South Wales: Elsevier, 2012

7. Halcomb E, Hickman L. Mixed methods research. Nurs Stand 2015;29:41-7.

8. Smith J, Cheater F, Bekker H, et al. Are parents and professionals making shared decisions about a child's care on presentation of a suspected shunt malfunction: a mixed method study? Health Expect 2015;18:1299-315.

9. Tashakkori A, Creswell JW. Editorial: exploring the nature of research questions in mixed methods research. J Mix Methods Res 2007;1:207-11.

10. Tashakkori A, Teddlie C, eds. Handbook of mixed methods in social and behavioral research. Thousand Oaks, CA: Sage, 2003.

11. Wisdom J, Creswell JW. Mixed methods: integrating quantitative and qualitative data collection and analysis while studying patient-centered medical home models. Rockville, MD: Agency for Healthcare Research and Quality, 2013.

12. National Collaborating Centre for Methods and Tools. Appraising qualitative, quantitative, and mixed methods studies included in mixed studies reviews: the MMAT. Hamilton, ON: McMaster University, 2015. http://www.nccmt.ca/resources/search/232 (accessed May 2017). 